International Journal of

Engineering Research and

Development

Cilt/Volume:14 Sayı/Issue:1 Ocak/January 2022

Araştırma Makalesi / Research Article

\title{
Correlation Between Surface, Thermal, Mechanical and Morphological Properties of Polylactic Acid/Polypropylene and Polylactic Acid/Polyamide 6 Blends
}

\author{
Sibel Tuna ${ }^{1,2}$ iD, Meral Akkoyun *,1 \\ ${ }^{1}$ Bursa Technical University, Polymer Materials Engineering, 16310, Bursa, TURKEY \\ ${ }^{2}$ Bursa Technical University, Central Research Laboratory, 16310, Bursa, TURKEY
}

Başvuru/Received: 09/06/2021

Kabul / Accepted: 23/07/2021

Çevrimiçi Basım / Published Online: 31/01/2022

Son Versiyon/Final Version: 31/01/2022

\begin{abstract}
In the automotive sector, which is one of the sectors where polymers are mostly used, their behaviour and compatibility in secondary processes such as painting and coating applications are important in the preference of polymers according to their usage areas as well as mechanical and thermal properties. In this context, it is known that surface wettability of a polymer material is of great importance for different application areas and it can be stated that wetting and non-wetting behaviours play an important role in the selection of polymers and their industrial applications. In this study, the contact angle properties of polypropylene (PP) and polyamide 6 (PA6), which are the most used polymers in the automotive sector and their polymer blends prepared by using polylactic acid (PLA) were examined. When PLA/PP and PLA/PA6 mixtures were compared, it was observed that there were significant differences in contact angle measurements and these properties detected in water contact angle measurements were attributed to changes in chemical structures, functional groups and morphology of related polymers. Surface analysis was supported by thermal, mechanical and morphological analysis and differences in static contact angle measurement results were explained.
\end{abstract}

\section{Key Words}

"Bio-based polymer blends, Wettability, Thermal properties, Mechanical properties, Morphological properties" 


\section{Introduction}

PP and PA6 are well-known engineering plastics in automotive industry with interesting properties. PP is one of the lightest thermoplastics among all automotive plastics with excellent properties such as good processability, high chemical resistance, good stiffness, good impact resistance and low cost. Bumpers, dashboards, door panels, grills, cable insulators are among the plastic parts where PP is mostly used in automobiles. PA6 is also a well-known polymer with its good mechanical properties and wear resistance and this polymer is frequently used when high mechanical strength, good abrasion, rigid and stable material is required. PA6 is mostly used in door handles and support parts due to its mechanical strength and wear resistance and under the engine hood due to its resistance to oil (Pradeep et al. 2017, Mallick 2021). Although their excellent performance and processability capabilities make engineering plastics a frequently preferred option, the vast majority of polymers which are produced from fossil fuels and treated with secondary processes such as painting, coating and plating, become waste in the environment where they do not degrade after the end of their service life and similar processes are repeated in terms of both environmental damage and consumption of limited fossil fuel resources in each new raw material production process. This vicious cycle has caused that given rise to the investigations of environmental, biobased and biodegradable polymers from renewable sources in recent years. Innovative and environmentally friendly production approaches, reducing fuel consumption of products and $\mathrm{CO}_{2}$ emissions are among the most important issues of recent years without compromising the performance of engineering plastics that have been used for years. Precisely at this point biopolymers have started to be considered as an alternative to petroleum-based polymers in long-term automotive applications due to their physical and mechanical behaviours, which have been better understood in recent years (Karimpour-Motlagh et al. 2020).

PLA is an aliphatic polyester which has been investigated in many applications in recent years with high tensile strength, high hardness and easy processability and has comparable properties with conventional petroleum-based polymers. In addition to its advantages, PLA has a number of limiting properties such as high cost, low toughness, low thermal resistance and low crystallization rate. However, it has been found in the studies that these limitations can be solved by preparing mixtures of different polymers, reinforcing fibers, micro and/or nanofillers and selected additives (Nampoothiri et al. 2010, Auras et al. 2003, Kawashima et al. 2005). Blending PLA with engineering plastics such as PP and PA6 has been considered to be a suitable solution to develop a new class of materials with improved mechanical properties and hydrolysis resistance, lower price and high degradability (Ploypetchara et al. 2014, Reddy et al. 2008, EbadiDehaghani et al. 2015).

While blending polymers is a simple technique used to enhance the poor properties of pure polymers, in some cases even more advanced properties can be obtained than the properties of pure polymers. There might be also situations where the obtained blends can be a solution to some needs in the current processes. It has been revealed that the use of PP/PA6 blends, which are among the most used polymers in the automotive industry for years, together with PLA brings out advanced features in surface properties as well as the thermal and mechanical properties, and the usage processes of these polymers can be affected by this situation.

The contact angle (CA) is a characterization of the surface properties expressed as wetting at a solid/liquid interface of polymers. Wetting is the interaction between a liquid and a solid, with the detection of a contact angle as a result of spreading of a liquid over a solid surface. Wetting and non-wetting properties have been among the outstanding studies in nature for years and the effects of this situation in industrial applications has started to be investigated in recent years. A great deal of industrial applications, such as textile finishing, plating, coating, printing processes, and microfluidic applications affect the wetting of solids by liquids (Grundke et al. 2015). To the best of our knowledge no studies exist concerning the surface properties examination of PLA/PP and PLA/PA6 polymer blends.

For a complete wetting, the equilibrium contact angle between a liquid and a solid surface is zero with the formation of a thin film by the liquid on the solid surface. When the contact angle value is greater than $90^{\circ}$ the solid surface is called as hydrophobic whereas the solid surface is considered as hydrophilic when the contact angle is less than $90^{\circ}$ (Figure 1). Whether the polymers are hydrophobic or hydrophilic is important for the finishing processes to be applied after their production. Preparing the polymers for the finishing process by blending without any intermediate process will create an advantage in terms of both time and cost.

In this work PLA/PP and PLA/PA6 blends with different content were prepared in order to observe changes in contact angle values. Thermal, mechanical and morphological analyses were performed to explain the results.

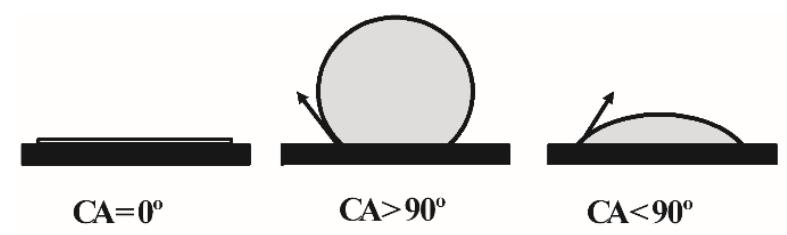

Figure 1. Different wetting situations of a solid surface. 


\section{Materials and Methods}

\subsection{Materials}

Polypropylene (BUPLEN) was supplied from Lukoil Petrochemical Company, Russia. The density and melt flow index of PP are $0.91 \mathrm{~g} / \mathrm{cm}^{3}$ and $7 \mathrm{~g} / 10 \mathrm{~min}\left(230^{\circ} \mathrm{C}, 2.16 \mathrm{~kg}\right)$, respectively. Polyamide 6 (Domamid 27) was provided from Ultra Polymers, Germany. The density of PA6 is $1.14 \mathrm{~g} / \mathrm{cm}^{3}$. Polylactic acid (Luminy L175) was purchased from Total Corbion, China. The density and melt flow index of PLA are $1.24 \mathrm{~g} / \mathrm{cm}^{3}$ and $8 \mathrm{~g} / 10 \min \left(210^{\circ} \mathrm{C}, 2.16 \mathrm{~kg}\right)$, respectively. All materials were used as received.

\subsection{Preparation of Polymer Blends}

PLA/PP and PLA/PA6 mixtures were prepared with a Polmak Plastik twin-screw extruder (co-rotating, $18 \mathrm{~mm}$ ). The temperatures were set at 90-190-195-200-205-210-210-210-210-210 ${ }^{\circ} \mathrm{C}$ for PLA/PP blends and 90-215-220-225-230-235-235-235-235-235 ${ }^{\circ} \mathrm{C}$ for PLA/PA6 blends, between the feeding part and the exit die. Before the extruder processing, PLA, PP and PA6 granules were dried in an oven at $80^{\circ} \mathrm{C}$ for 2 hours to remove moisture content. Then, dried PLA, PP and PA6 granules were premixed according to the formulation ratios given in Table 1 and fed into a hopper for extrusion process.

Table 1. Formulations of PLA/PP and PLA/PA6 polymer blends

\begin{tabular}{lccc}
\hline Samples & PLA (wt.\%) & PP (wt.\%) & PA6 (wt.\%) \\
\hline Neat PLA & 100 & - & - \\
Neat PP & - & 100 & - \\
Neat PA6 & - & - & 100 \\
PLA/PP (20:80) & 20 & 80 & - \\
PLA/PP (30:70) & 30 & 70 & - \\
PLA/PP (40:60) & 40 & 60 & - \\
PLA/PP (70:30) & 70 & 30 & - \\
PLA/PA6 (20:80) & 20 & - & 80 \\
PLA/PA6 (30:70) & 30 & - & 70 \\
PLA/PA6 (40:60) & 40 & - & 60 \\
PLA/PA6 (70:30) & 70 & - & 30 \\
\hline
\end{tabular}

Homogenously mixed blends were shaped in a filament form through the die, cooled in a water bath and cut into granules. Then, for each composition, the obtained pellets were dried in an oven at $80^{\circ} \mathrm{C}$ for 2 hours to remove moisture content and were molded to obtain $250 \times 250 \times 4 \mathrm{~mm}$ plates using a CARVER/12-12 compression molding machine under a pressure of 4 bars and at $200^{\circ} \mathrm{C}$ and $225^{\circ} \mathrm{C}$ for PLA/PP and PLA/PA6 blends, respectively.

\subsection{Characterization Methods}

2.3.1. FT-IR analysis

Fourier transform infrared (FT-IR) spectroscopy measurements were performed using a Thermoscientific/Nicolet-IS50 spectrophotometer. The interactions between the polymers were evaluated at a wavelength range of $4000-600 \mathrm{~cm}^{-1}$.

\subsubsection{Mechanical analysis}

Tensile test measurements of polymer blends were performed at room temperature using a universal testing machine (Shimadzu/AGS$\mathrm{X}$ ) and Young's modulus, tensile strength, and elongation at break parameters were examined according to ASTM D638. Crosshead speed and load cell were fixed at $5 \mathrm{~mm} / \mathrm{min}$ and $10 \mathrm{kN}$, respectively. The average values of at least five measurements were reported.

\subsubsection{Thermal analysis}

These measurements were carried out using a differential scanning calorimeter (TA Instrument/DSC25). For the purpose of determination of glass transition temperature (Tg), melting temperature ( $\mathrm{Tm})$ and cold crystallization temperature (Tc), heat-cool-heat method was applied. The specimens were heated from $20^{\circ} \mathrm{C}$ to $250^{\circ} \mathrm{C}$ at $5^{\circ} \mathrm{C} / \mathrm{min}$ and held at that temperature for 2 minutes. Then, the samples were cooled to $20^{\circ} \mathrm{C}$ at a cooling rate of $5^{\circ} \mathrm{C} / \mathrm{min}$ and heated again to $250^{\circ} \mathrm{C}$ at $5^{\circ} \mathrm{C} / \mathrm{min}$ under constant nitrogen flow.

\subsubsection{Morphological analysis}

The morphology of polymer blends was evaluated using a Carl Zeiss (Gemini 300) scanning electron microscopy (SEM) at $5 \mathrm{kV}$ and different magnification rates. Prior to imaging, the blends were all coated with $15 \mathrm{~nm} \mathrm{Au/Pd}$ alloy (Leica/ACE600) to avoid charging artefacts by ion sputtering method device. 


\subsubsection{Surface properties analysis}

Static water contact angles of polymer blends were detected using a Biolin Scientific (ThetaFlex) optical tensiometer and the sessile drop technique was applied. $5 \mu \mathrm{L}$ of distilled water droplet was introduced on the sample surface through an automatic pipet. Then, photographs were taken after stabilization of the drop. Measurements were performed on three different surface areas and average contact angle values were calculated.

\section{Results and Discussions}

\subsection{Chemical Structure of Polymer Blends}

The FT-IR spectrum of pure polymers (PLA, PP and PA6) and polymer blends (PLA/PP and PLA/PA6) were shown in Figure 2. The characteristic peaks of neat PP at 2950-2838 cm $-\mathrm{CH}_{3}$ bending, respectively (as seen in Figure 2(a)). When the FT-IR spectrum of the neat PLA is evaluated, the C=O stretching peak at the wavelength $1750 \mathrm{~cm}^{-1}$, the symmetrical $\mathrm{C}-\mathrm{O}-\mathrm{C}$ stretching peak at the wavelength $1180 \mathrm{~cm}^{-1}$ and the asymmetric $\mathrm{CH}_{3}$ peak at the wavelength $1080 \mathrm{~cm}^{-1}$ can be observed. Figure 2(a) also indicated the PLA and PP interactions and the change in the peak intensity around the wavelengths $1750 \mathrm{~cm}^{-1}, 1180 \mathrm{~cm}^{-1}$ and $1080 \mathrm{~cm}^{-1}$ significantly.

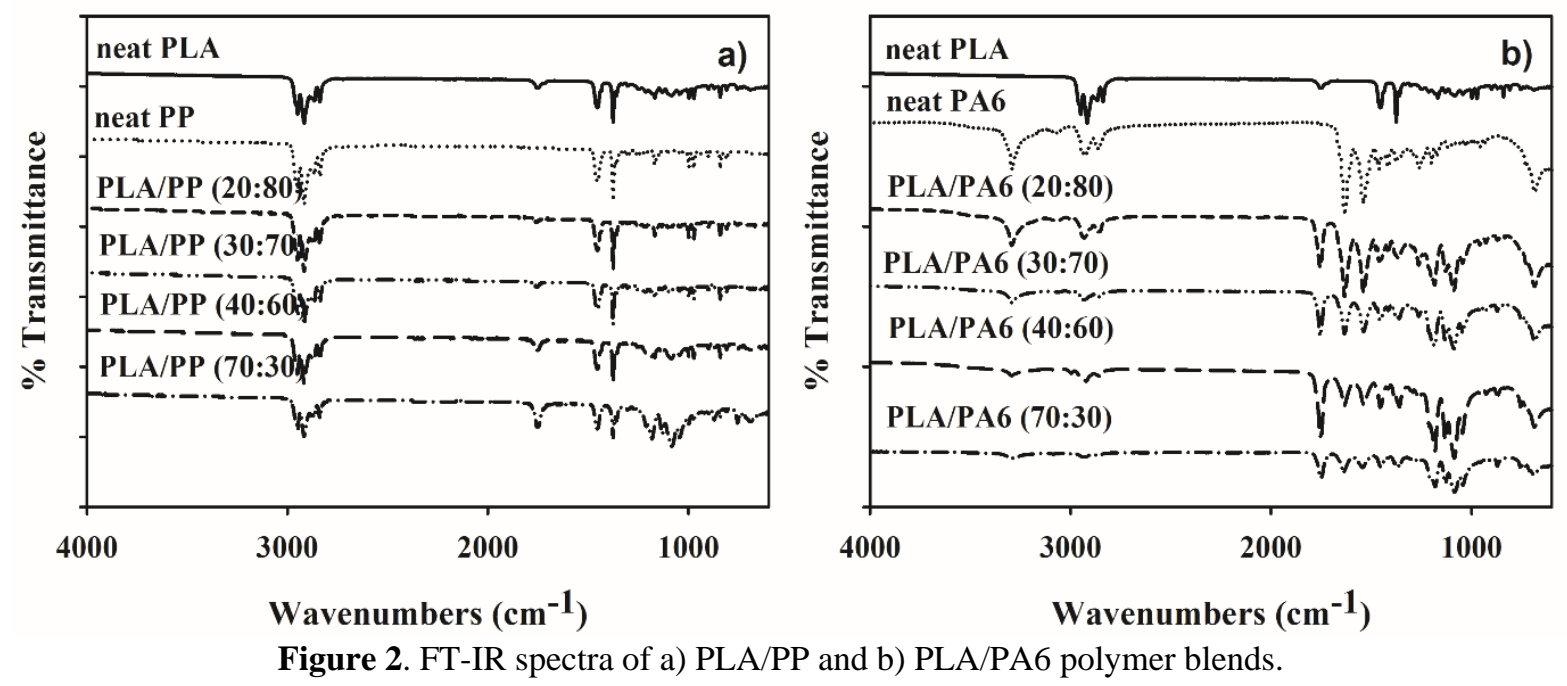

On the other hand, Figure 2(b) represents the FT-IR spectrum of neat PLA, neat PA6 and PLA/PA6 polymer blends. The characteristic peaks of neat PA6 at $3300 \mathrm{~cm}^{-1}, 2931-2865 \mathrm{~cm}^{-1}$ and $1632 \mathrm{~cm}^{-1}$ were connected to $\mathrm{N}-\mathrm{H}$ stretching, $\mathrm{C}-\mathrm{H}$ stretching and $\mathrm{C}=\mathrm{O}$ stretching, respectively. The specific transmittance bands of PLA/PA6 polymer blends were observed around the wavelengths $3300 \mathrm{~cm}^{-1}$ and 1757 $\mathrm{cm}^{-1}$ related to $\mathrm{N}-\mathrm{H}$ stretching peak of the amide group of PA6 and $\mathrm{C}=\mathrm{O}$ stretching peak of the carbonyl group of PLA, respectively (Figure 3). It can be also stated that the shift observed in the stretching peak of the carbonyl group in polymer blends is related to the hydrogen bond interactions occurring between PLA and PA6 molecules (Feng and Ye 2010).

It can be also observed that the intensity of the $\mathrm{C}=\mathrm{O}$ stretching in the $1750 \mathrm{~cm}^{-1}$ band of the PLA, the $\mathrm{C}-\mathrm{O}-\mathrm{C}$ stretching in the 1180 $\mathrm{cm}^{-1}$ band and the asymmetric $\mathrm{CH}_{3}$ peaks in the $1080 \mathrm{~cm}^{-1}$ band vary depending on the PLA ratio in the PLA/PA6 polymer blends. These FT-IR spectrums reveal that PLA, PP and PA6 polymers continue to show their own characteristic properties in polymer blends and do not form a very compatible structure in the mixtures (Pivsa-Art et al. 2016).

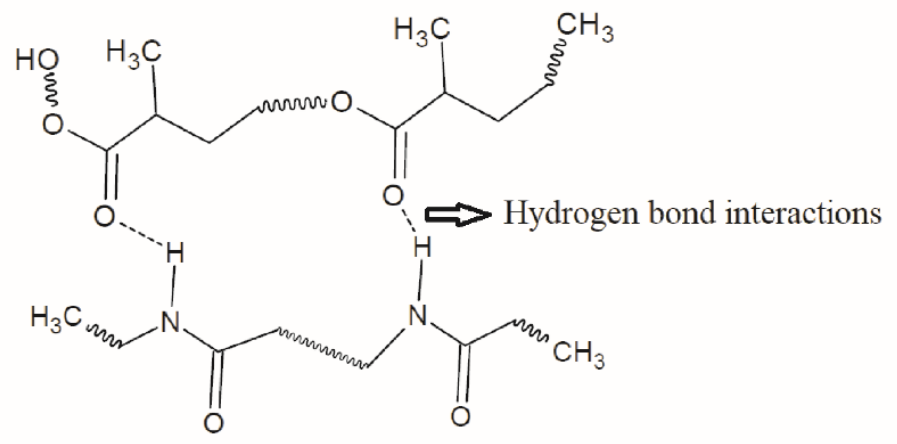

Figure 3. Schematic representation of hydrogen bond interaction between PLA and PA6 polymers. 


\subsection{Mechanical Properties of Polymer Blends}

Table 2 displays the effect of PLA content on the mechanical properties of PLA/PP and PLA/PA6 polymer blends. It can be observed that as PP ratio increases and PLA ratio decreases in polymer blends, the elastic modulus and tensile strength values decrease. It can be concluded that the structure of the polymer blend passes from a ductile form to a brittle one. From the tensile test results of PLA/PA6 blends, it can be observed that as the PLA ratio rises and the PA6 ratio decreases in the polymer blends, the elastic modulus increases while a depletion of the tensile strength and elongation at break values is obtained. Among PLA/PA6 polymer blends for which mechanical properties are weakened by increasing PLA ratio, it can be stated that the formulation with the lowest PLA content has the highest tensile strength and elongation at break values. All these results are in correlation with the literature (Feng and Ye 2010).

Table 2. Tensile test results of PLA/PP and PLA/PA6 polymer blends

\begin{tabular}{lccc}
\hline Samples & $\begin{array}{c}\text { Elastic Modulus } \\
\left(\mathbf{N} / \mathbf{m m}^{\mathbf{2}}\right)\end{array}$ & $\begin{array}{c}\text { Tensile Strength } \\
(\mathbf{M P a})\end{array}$ & $\begin{array}{c}\text { Elongation at Break } \\
(\boldsymbol{\%})\end{array}$ \\
\hline Neat PLA & $2714.9 \pm 40.869$ & $31.3 \pm 1.29$ & $1.40 \pm 0.06$ \\
Neat PP & $1511.5 \pm 15.464$ & $33.3 \pm 0.78$ & $7.42 \pm 0.01$ \\
Neat PA6 & $1111.6 \pm 16.674$ & $25.7 \pm 0.38$ & $6.15 \pm 0.01$ \\
PLA/PP (20:80) & $1690.0 \pm 35.169$ & $18.1 \pm 2.17$ & $1.32 \pm 0.23$ \\
PLA/PP (30:70) & $1926.1 \pm 30.285$ & $25.2 \pm 0.34$ & $2.51 \pm 0.53$ \\
PLA/PP (40:60) & $1928.4 \pm 25.018$ & $21.2 \pm 0.67$ & $1.41 \pm 0.13$ \\
PLA/PP (70:30) & $2330.8 \pm 54.079$ & $26.8 \pm 4.91$ & $1.35 \pm 0.22$ \\
PLA/PA6 (20:80) & $1164.0 \pm 42.263$ & $30.7 \pm 5.70$ & $6.97 \pm 1.84$ \\
PLA/PA6 (30:70) & $1306.5 \pm 49.853$ & $22.7 \pm 1.92$ & $2.71 \pm 0.79$ \\
PLA/PA6 (40:60) & $1109.3 \pm 46.779$ & $18.8 \pm 5.50$ & $2.18 \pm 0.72$ \\
PLA/PA6 (70:30) & $1759.9 \pm 47.644$ & $16.8 \pm 3.05$ & $1.10 \pm 0.28$ \\
\hline
\end{tabular}

\subsection{Thermal Properties of Polymer Blends}

Thermal properties of PLA/PP and PLA/PA6 polymer blends were evaluated through the glass transition temperatures (Tg) $\left(1^{\text {st }}\right.$ heating), melting temperatures $\left(\mathrm{Tm}_{1}\right.$ and $\left.\mathrm{Tm}_{2}\right)\left(1^{\text {st }}\right.$ and $2^{\text {nd }}$ heating) and crystallization temperatures $(\mathrm{Tc})\left(1^{\text {st }}\right.$ cooling) detected from DSC thermograms. All results were gathered in Figure 4-5 and Table 3.

As shown in Table 3 and Figure 4, it is observed that there is no significant change for Tg and Tm of PLA/PP polymer blends with increasing the PLA content. This situation shows that the polymer ratios of semi-crystalline PLA and semi-crystalline PP do not affect the crystal structure formation in blends consisting of incompatible polymers as observed in the literature (Ploypetchara et al. 2014). Therefore, Tc values of the blends are similar to those of the neat components.

Figure 5 and Table 3 displays thermal transitions of PLA/PA6 polymer blends and it can be seen that Tg values are similar to that of neat PLA and PA6 polymers. When the melting peaks that occur during the first and second heating in DSC thermograms are evaluated, it can be observed that a secondary shoulder melting peak is formed especially in the case of the second heating. Such a result is probably due to the interactions of the semi-crystalline structure of PLA with the PA6 (Di et al. 2005, Stoclet et al. 2011, He et al. 2008). Accordingly, it can be stated that the presence of $\alpha$-form pseudo-orthorhombic crystal structures which display melting behaviour at high temperatures and $\beta$-form orthorhombic crystal structures displaying melting behaviour at lower temperatures cause this shouldering in the melting peaks of PLA (Pan and Inoue 2009). 

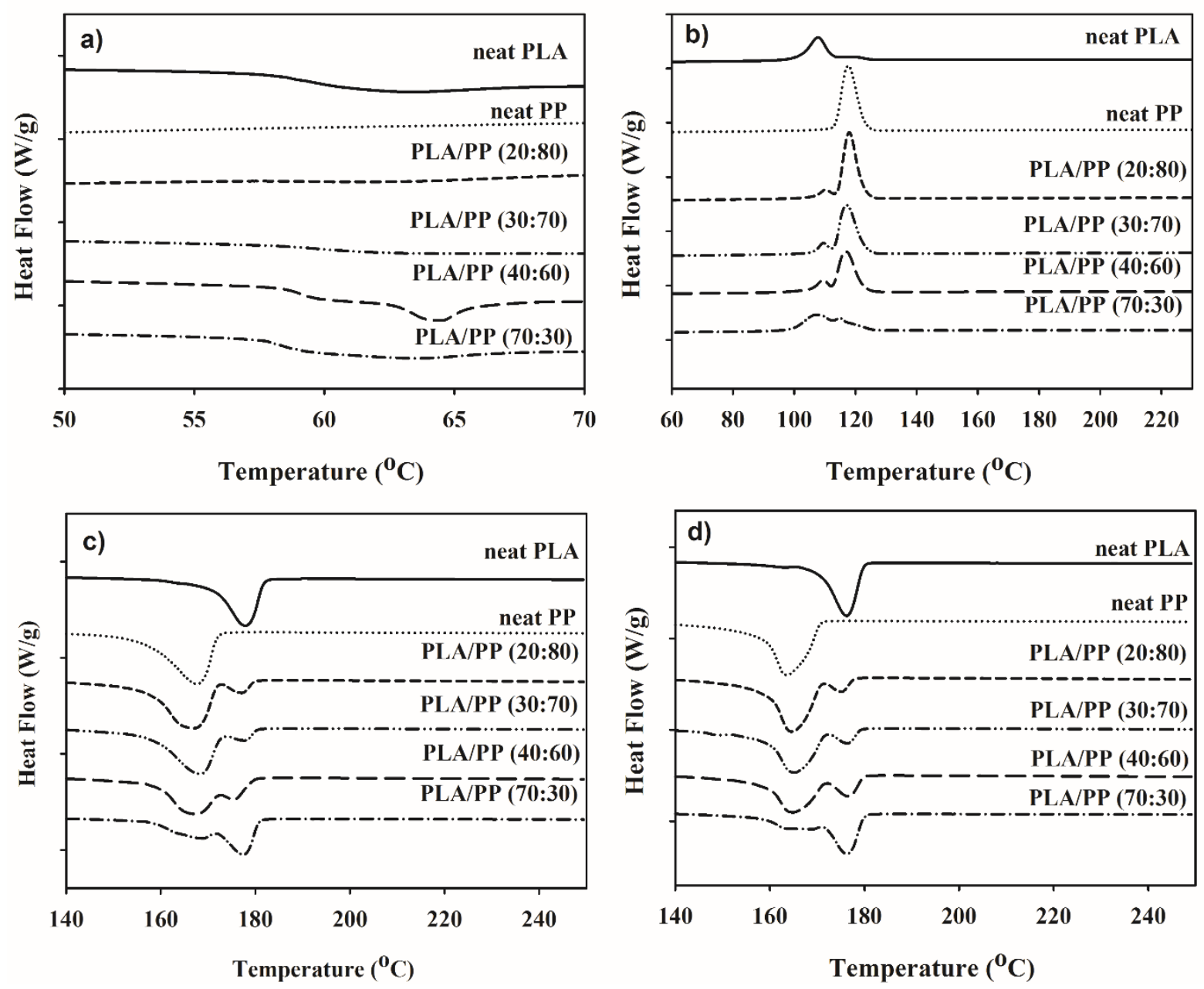

Figure 4. DSC thermograms of PLA/PP blends (a) glass transition (b) cold crystallization c) first melting transition and d) second melting transition

On the other hand, the crystallization peaks of PLA/PA6 polymer blends show that, the peak at $190^{\circ} \mathrm{C}$ caused by the crystallization of the PA6 polymer can be clearly seen, while, the crystallization peak of PLA cannot be observed clearly. By increasing PLA ratio there is another exothermic peak around $90^{\circ} \mathrm{C}$ that can be seen in DSC thermograms.

Considering that the crystallization temperature of PLA in its neat form is around $107^{\circ} \mathrm{C}$, it can be stated that this decrease is caused by hydrogen bonds interactions formed between the amide groups $(\mathrm{N}-\mathrm{H})$ of PA6 and the carbonyl groups $(\mathrm{C}=\mathrm{O})$ of the PLA (Khankrua et al. 2014). 

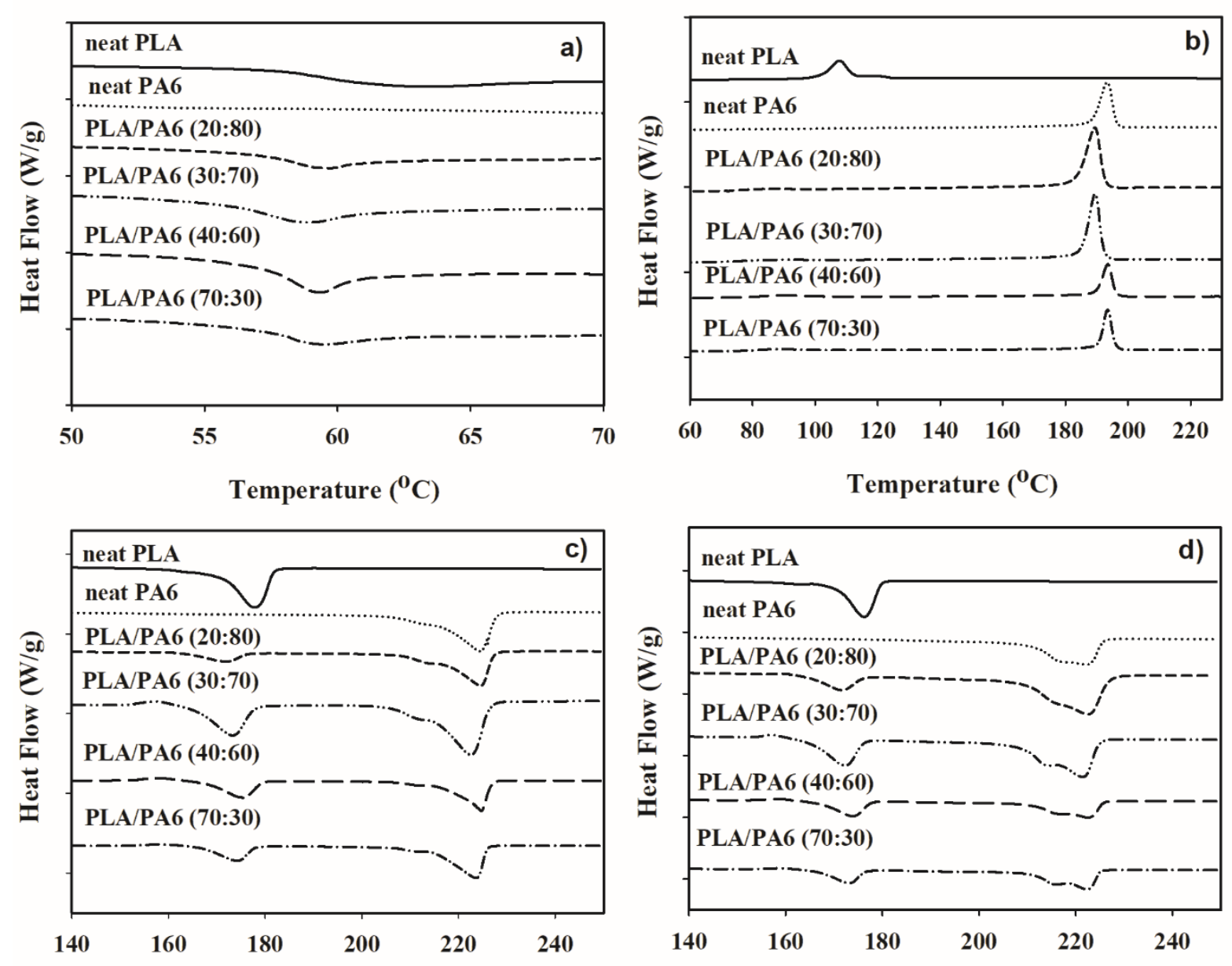

Temperature $\left({ }^{\circ} \mathrm{C}\right)$

Temperature $\left({ }^{0} \mathrm{C}\right)$

Figure 5. DSC thermograms of PLA/PA6 blends (a) glass transition (b) cold crystallization c) first melting transition and d) second melting transition

\subsection{Morphology of Polymer Blends}

The morphology of polymer blends can vary according to several parameters such as the polymer ratios in the mixture, the elasticity and compatibility of the phases and the viscosity ratios. Figure 6 shows SEM images of PLA/PP and PLA/PA6 polymer blends.

From this Figure 6 , in the case of PLA/PP compositions, due to the distinct viscosities of polymers $(\eta \mathrm{PP} / \eta \mathrm{PLA}>1)$ and using these polymers in different ratios, a droplet-matrix morphology can be observed. In this sense, the polymer in lower amount in the blend is dispersed by forming spherical droplets in the polymer used at higher rates (Hamad et al. 2018, Sui et al. 2018, Bhasney et al. 2020). On the other hand, from SEM images of PLA/PA6 polymer mixtures, the small dimensions of polymer spheres observed in the structure and the homogeneous distribution in the matrix can be interpreted as the compatibility between PLA and PA6 polymers, and thus the low interface energy. This situation can be explained by the hydrogen bond interactions expected to form between the amide groups $(\mathrm{N}-\mathrm{H})$ of PA6 and the carbonyl groups (C=O) of PLA (Stoclet et al. 2011).

Table 3. Thermal analysis results of neat polymers (PLA, PP and PA6) and polymer blends (PLA/PP and PLA/PA6)

\begin{tabular}{|c|c|c|c|c|c|c|c|}
\hline \multirow[t]{2}{*}{ Samples } & \multirow{2}{*}{$\begin{array}{c}\text { Glass Transition } \\
\text { Temperature } \\
\operatorname{Tg}\left({ }^{\circ} \mathrm{C}\right) \\
1^{\text {st }} \text { heating }\end{array}$} & \multicolumn{2}{|c|}{$\begin{array}{c}\text { Melting } \\
\text { Temperature } \\
\operatorname{Tm}_{1}\left({ }^{\circ} \mathrm{C}\right)\end{array}$} & \multicolumn{2}{|c|}{$\begin{array}{c}\text { Melting } \\
\text { Temperature } \\
\operatorname{Tm}_{2}\left({ }^{\circ} \mathbf{C}\right)\end{array}$} & \multicolumn{2}{|c|}{$\begin{array}{c}\text { Crystallization } \\
\text { Temperature } \\
1^{\text {st }} \text { cooling }\end{array}$} \\
\hline & & $\begin{array}{c}1^{\text {st }} \\
\text { heating }\end{array}$ & $\begin{array}{c}2^{\text {nd }} \\
\text { heating }\end{array}$ & $\begin{array}{c}1^{\text {st }} \\
\text { heating }\end{array}$ & $\begin{array}{c}2^{\text {nd }} \\
\text { heating }\end{array}$ & $\mathrm{Tc}_{1}\left({ }^{\circ} \mathrm{C}\right)$ & $\mathrm{Tc}_{2}\left({ }^{\circ} \mathrm{C}\right)$ \\
\hline Neat PLA & 59.22 & 177.9 & 176.2 & - & - & 107.7 & - \\
\hline Neat PP & - & - & - & 167.9 & 163.6 & - & 117.6 \\
\hline Neat PA6 & - & 224.6 & 222.4 & - & - & 193.3 & - \\
\hline
\end{tabular}


Table 3 (cont.). Thermal analysis results of neat polymers (PLA, PP and PA6) and polymer blends (PLA/PP and PLA/PA6)

\begin{tabular}{|c|c|c|c|c|c|c|c|}
\hline \multirow[t]{2}{*}{ Samples } & \multirow{2}{*}{$\begin{array}{c}\text { Glass Transition } \\
\text { Temperature } \\
\operatorname{Tg}\left({ }^{\circ} \mathrm{C}\right) \\
1^{\text {st }} \text { heating }\end{array}$} & \multicolumn{2}{|c|}{$\begin{array}{c}\text { Melting } \\
\text { Temperature } \\
\operatorname{Tm}_{1}\left({ }^{\circ} \mathrm{C}\right)\end{array}$} & \multicolumn{2}{|c|}{$\begin{array}{c}\text { Melting } \\
\text { Temperature } \\
\operatorname{Tm}_{2}\left({ }^{\circ} \mathrm{C}\right)\end{array}$} & \multicolumn{2}{|c|}{$\begin{array}{c}\text { Crystallization } \\
\text { Temperature } \\
1^{\text {st }} \text { cooling }\end{array}$} \\
\hline & & $\begin{array}{c}1^{\text {st }} \\
\text { heating }\end{array}$ & $\begin{array}{c}2^{\text {nd }} \\
\text { heating }\end{array}$ & $\begin{array}{c}1^{\text {st }} \\
\text { heating }\end{array}$ & $\begin{array}{c}2^{\text {nd }} \\
\text { heating }\end{array}$ & $\operatorname{Tc}_{1}\left({ }^{\circ} \mathrm{C}\right)$ & $\mathrm{Tc}_{2}\left({ }^{\circ} \mathbf{C}\right)$ \\
\hline PLA/PP (20:80) & 59.53 & 177.2 & 175.2 & 167.1 & 164.7 & 110.2 & 118.0 \\
\hline PLA/PP (30:70) & 60.07 & 177.7 & 176.5 & 168.4 & 165.2 & 109.5 & 117.0 \\
\hline PLA/PP (40:60) & 60.19 & 175.6 & 176.7 & 167.6 & 164.8 & 109.4 & 116.8 \\
\hline PLA/PP (70:30) & 58.54 & 177.6 & 176.4 & 169.0 & 170.4 & 107.0 & 114.7 \\
\hline PLA/PA6 (20:80) & 57.74 & 171.9 & 171.5 & 224.6 & 222.5 & - & 193.6 \\
\hline PLA/PA6 (30:70) & 58.89 & 173.3 & 172.2 & 222.6 & 221.5 & - & 189.4 \\
\hline PLA/PA6 (40:60) & 57.98 & 175.2 & 173.8 & 222.7 & 222.7 & - & 193.6 \\
\hline PLA/PA6 (70:30) & 58.12 & 174.3 & 173.2 & 223.8 & 222.5 & - & 193.4 \\
\hline
\end{tabular}
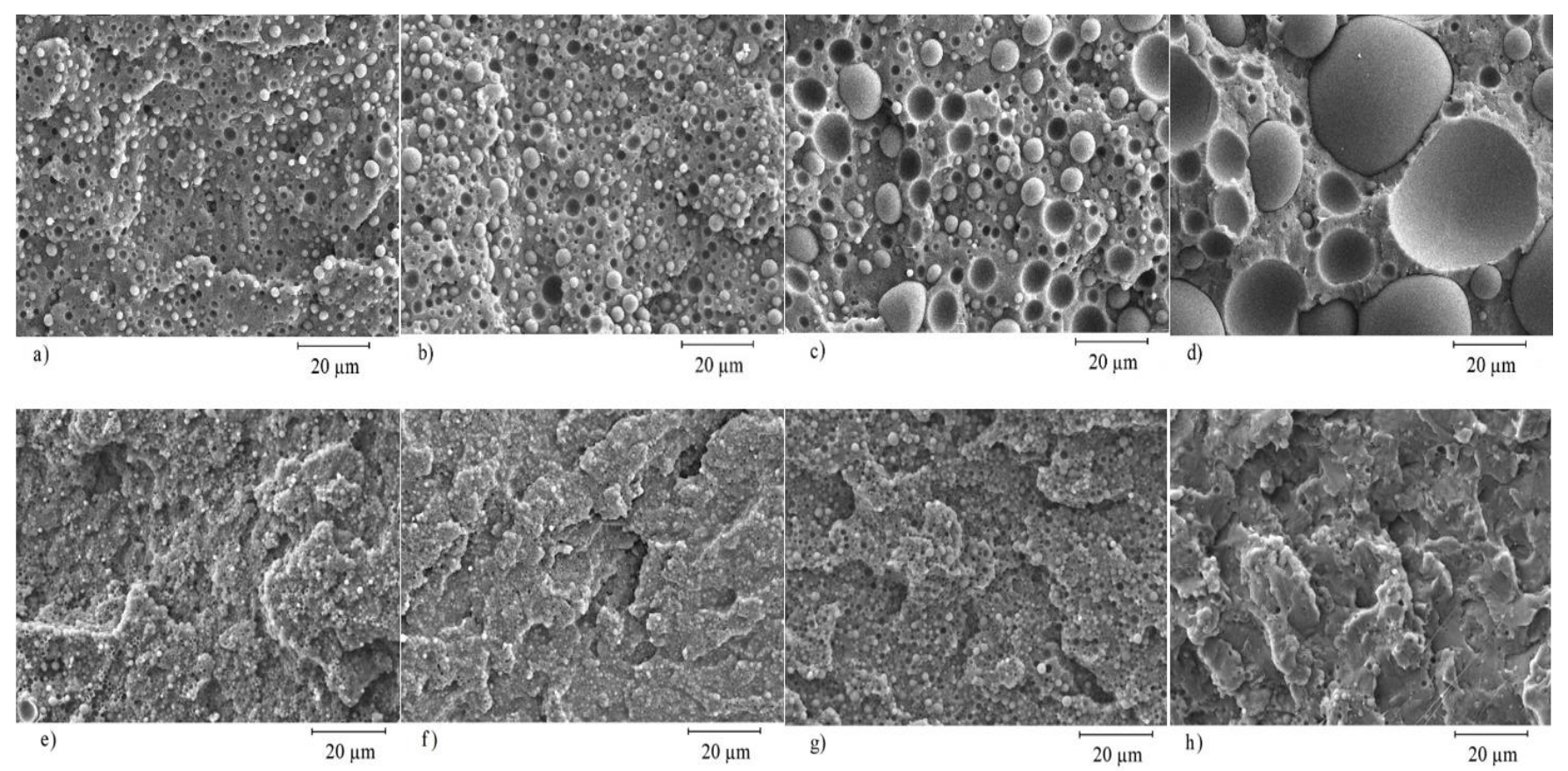

Figure 6. SEM images of a) PLA/PP (20:80), b) PLA/PP (30:70), c) PLA/PP (40:60), d) PLA/PP (70:30), e) PLA/PA6 (20:80), f) PLA/PA6 (30:70), g) PLA/PA6 (40:60) and h) PLA/PA6 (70:30) obtained at a magnification of $\times 1000$

\subsection{Surface Properties of Polymer Blends}

Figure 7- 8 and Table 4 present the contact angle analysis results of neat polymers (PLA, PP and PA6) and polymer blends (PLA/PP and PLA/PA6). According to these results, it can be clearly seen that the contact angle value of the neat PP is higher than the contact angle value of the neat PLA. In other words, it can be stated that PP is more hydrophobic than PLA. As a result, depending on the polymer ratio used in the PLA/PP polymer blends, it can be observed that there are expected differences between contact angle values of these polymer blends. While no major differences were detected in the contact angle values of PLA/PP polymer blends, it can be seen that the contact angle values of PLA/PA6 blends significantly decreased compared to the neat PLA and PA6 polymer. This decrease in the contact angle values of PLA/PA6 polymer blends is thought to increase the hydrophilic properties of the structures due to the expected hydrogen bond interactions between the amide groups $(\mathrm{N}-\mathrm{H})$ in the PA6 and the carbonyl groups $(\mathrm{C}=\mathrm{O})$ in the PLA. 
a) b

b)

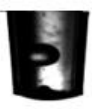

c)

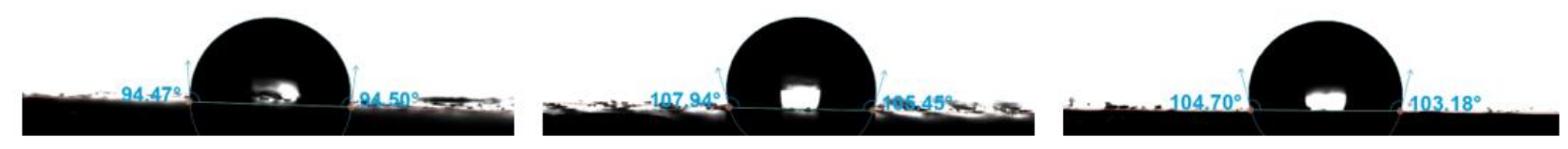

Figure 7. Contact angle images of a) neat PLA, b) neat PP and c) neat PA6 a)

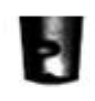

b)

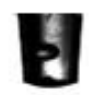

c)

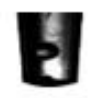

d)

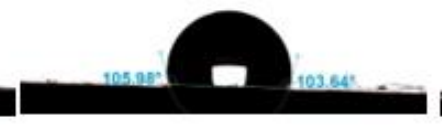

f)

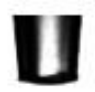

g)

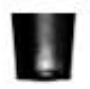

h)

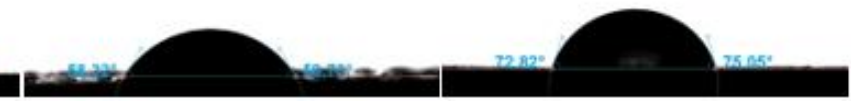

Figure 8. Contact angle images of a) PLA/PP (20:80), b) PLA/PP (30:70), c) PLA/PP (40:60), d) PLA/PP (70:30), e) PLA/PA6 (20:80), f) PLA/PA6 (30:70), g) PLA/PA6 (40:60) and h) PLA/PA6 (70:30)

Table 4. Contact angle values of neat polymers (PLA, PP and PA6) and polymer blends (PLA/PP and PLA/PA6)

\begin{tabular}{lc}
\hline Samples & Contact angle $\left(^{\circ}\right)$ \\
\hline Neat PLA & $94.50 \pm 2.450$ \\
Neat PP & $106.7 \pm 2.872$ \\
Neat PA6 & $103.9 \pm 3.186$ \\
PLA/PP (20:80) & $102.6 \pm 4.351$ \\
PLA/PP (30:70) & $104.8 \pm 3.876$ \\
PLA/PP (40:60) & $99.00 \pm 3.410$ \\
PLA/PP (70:30) & $96.20 \pm 4.160$ \\
PLA/PA6 (20:80) & $60.90 \pm 3.980$ \\
PLA/PA6 (30:70) & $60.10 \pm 4.070$ \\
PLA/PA6 (40:60) & $59.00 \pm 4.570$ \\
PLA/PA6 (70:30) & $73.90 \pm 3.430$ \\
\hline
\end{tabular}

\section{Conclusions}

PLA/PP and PLA/PA6 polymer blends were prepared by extrusion and molded by compression molding processes. As a result of this work, it was seen that the thermal and mechanical properties of PLA/PP and PLA/PA6 mixtures were improved compared to pure PLA. On the other hand, SEM results showed that a very compatible interface interaction and structure did not occur between PLA and PP, while a much more compatible structure was formed between PLA and PA6 mainly due to the interactions between amide groups (N- 
$\mathrm{H})$ of PA6 and the carbonyl groups $(\mathrm{C}=\mathrm{O})$ of PLA. It was observed that the interactions that caused this compatible structure also affected the contact angle results. In this sense, no significant differences were observed in the contact angle values of PLA/PP mixtures whereas the contact angle values of PLA/PA6 blends decreased remarkably and hydrophilic structures appeared. Considering the surface treatments applied to parts in the automotive sector, it can be foreseen that this hydrophilic property gained by PLA/PA6 polymer blends can be transformed into an advantage in various processes such as painting, coating, plating and it is aimed to detail the studies to be carried out in this regard.

\section{Acknowledgement}

The authors gratefully acknowledge the Scientific Research Projects Unit of Bursa Technical University (under the contract number of 190D001) and Bursa Technical University Central Research Laboratory for providing facilities for this research.

\section{References}

Auras, R. A., Harte, B., Selke, S., \& Hernandez, R. (2003). Mechanical, physical, and barrier properties of poly (lactide) films. Journal of Plastic Film \& Sheeting, 19(2), 123-135. doi:10.1177/8756087903039702

Bhasney, S. M., Kumar, A., \& Katiyar, V. (2020). Microcrystalline cellulose, polylactic acid and polypropylene biocomposites and its morphological, mechanical, thermal and rheological properties. Composites Part B: Engineering, 184, 107717. doi:10.1016/j.compositesb.2019.107717

Di, Y., Iannace, S., Di Maio, E., \& Nicolais, L. (2005). Reactively modified poly (lactic acid): properties and foam processing," Macromolecular Materials and Engineering., 290(11), 1083-1090. doi:10.1002/mame.200500115

Ebadi-Dehaghani, H., Khonakdar, H. A., Barikani, M., \& Jafari, S. H. (2015). Experimental and theoretical analyses of mechanical properties of PP/PLA/clay nanocomposites. Composites Part B: Engineering, 69, 133-144. doi:10.1016/j.compositesb.2014.09.006

Feng, F., \& Ye, L. (2010). Structure and property of polylactide/polyamide blends. Journal of Macromolecular Science, Part B Physics, 49(6), 1117-1127. doi:10.1080/00222341003609179

Grundke, K., Pöschel, K., Synytska, A., Frenzel, R., Drechsler, A., Nitschke, M., Cordeiro, A. L., Uhlmann, P., \& Welzel, P. B. (2015). Experimental studies of contact angle hysteresis phenomena on polymer surfaces-Toward the understanding and control of wettability for different applications. Advances in Colloid and Interface Science, 222, 350-376. doi:10.1016/j.cis.2014.10.012

Hamad, K., Kaseem, M., Ayyoob, M., Joo, J., \& Deri, F. (2018). Polylactic acid blends: The future of green, light and tough. Progress in Polymer Science, 85, 83-127. doi:10.1016/j.progpolymsci.2018.07.001

He, Y., Xu, Y., Wei, J., Fan, Z., \& Li, S. (2008). Unique crystallization behavior of poly (L-lactide)/poly (D-lactide) stereocomplex depending on initial melt states. Polymer, 49(26), 5670-5675. doi:10.1016/j.polymer.2008.10.028

Karimpour-Motlagh, N., Khonakdar, H. A., Jafari, S. M. A., Mahjub, A., Panahi-Sarmad, M., Kasbi, S. F., Shojaei, S., Goodarzi, V., \& Arjmand, M. (2020). Influence of polypropylene and nanoclay on thermal and thermo-oxidative degradation of poly (lactide acid): TG-FTIR, TG-DSC studies and kinetic analysis. Thermochimica Acta, 691, 178709. doi:10.1016/j.tca.2020.178709

Kawashima, N., Ogawa, S., Obuchi, S., Matsuo, M., \& Yagi, T. (2005). Polylactic acid 'LACEA'. Biopolymer Online, 4. doi:10.1002/3527600035.bpol4009

Khankrua, R., Pivsa-Art, S., Hiroyuki, H., \& Suttiruengwong, S. (2014). Effect of chain extenders on thermal and mechanical properties of poly (lactic acid) at high processing temperatures: Potential application in PLA/Polyamide 6 blend. Polymer Degradation and Stability, 108, 232-240. doi:10.1016/j.polymdegradstab.2014.04.019

Mallick, P. K. (2021). Thermoplastics and thermoplastic-matrix composites for lightweight automotive structures. Materials, design and manufacturing for lightweight vehicles. MA: Woodhead Publishing.

Nampoothiri, K. M., Nair, N. R., \& John, R. P. (2010). An overview of the recent developments in polylactide (PLA) research. Bioresource Technology, 101(22), 8493-8501. doi:10.1016/j.biortech.2010.05.092

Pan, P., \& Inoue, Y. (2009). Polymorphism and isomorphism in biodegradable polyesters. Progress in Polymer Science, 34(7), 605640. doi:10.1016/j.progpolymsci.2009.01.003

Pivsa-Art, S., Kord-Sa-Ard, J., Pivsa-Art, W., Wongpajan, R., O-Charoen, N., Pavasupree, S., \& Hamada, H. (2016). Effect of compatibilizer on PLA/PP blend for injection molding. Energy Procedia, 89, 353-360. doi:10.1016/j.egypro.2016.05.046 
Ploypetchara, N., Suppakul, P., Atong, D., \& Pechyen, C. (2014). Blend of polypropylene/poly (lactic acid) for medical packaging application: physicochemical, thermal, mechanical, and barrier properties. Energy Procedia, 56, 201-210. doi:10.1016/j.egypro.2014.07.150

Pradeep, S. A., Iyer, R. K., Kazan, H., \& Pilla, S. (2017). Automotive applications of plastics: past, present, and future. Applied Plastics Engineering Handbook (2nd ed.). MA: William Andrew.

Reddy, N., Nama, D., \& Yang, Y. (2008). Polylactic acid/polypropylene polyblend fibers for better resistance to degradation. Polymer Degradation and Stability, 93(1), 233-241. doi:10.1016/j.polymdegradstab.2007.09.005

Stoclet, G., Seguela, R., \& Lefebvre, J.-M. (2011). Morphology, thermal behavior and mechanical properties of binary blends of compatible biosourced polymers: Polylactide/polyamide11. Polymer, 52(6), 1417-1425. doi:10.1016/j.polymer.2011.02.002

Sui, G., Jing, M., Zhao, J., Wang, K., Zhang, Q., \& Fu, Q. (2018). A comparison study of high shear force and compatibilizer on the phase morphologies and properties of polypropylene/polylactide (PP/PLA) blends. Polymer, 154, 119-127. doi:10.1016/j.polymer.2018.09.005 